\title{
Knowledge of Healthcare Workers on Immunization: New and Under- utilized and Perception towards Future Vaccines
}

\author{
Jibo $\mathrm{AM}^{1^{*}}$ Karaye $\mathrm{RS}^{2}$, Gajida $\mathrm{AU}^{1}$, Abulfathi $\mathrm{AA}^{3}$ \\ ${ }^{I}$ Department of Community Medicine, Bayero University Kano \\ ${ }^{2}$ Department of Pediatrics, Murtala Mohammed Specialist Hospital, Kano \\ ${ }^{3}$ Department of Community Medicine, Aminu Kano Teaching Hospital, Kano
}

\author{
*Corresponding Author: Dr A.M. Jibo. Department of Community Medicine, Bayero University Kano, Kano, Nigeria \\ Email: ajmohammed.cmed@buk.edu.ng.
}

\begin{abstract}
Nigeria is making effort to address the child mortality burden by increasing vaccine coverage rates, yet the vaccine coverage falls short of $90 \%$ target. Scaling up of new and under-used vaccines to $90 \%$ coverage could save more than 600,000 Nigerian children. Healthcare givers knowledge of vaccine used for immunization is essential to increase the vaccine uptake rates. This study assesses the knowledge of routine, underutilized and future vaccines among health workers. A cross sectional descriptive study was done among health care workers at a tertiary health facility in Nigeria. Using a pre-tested semi structured interviewer administered questionnaire, 220 respondents were selected by cluster sampling technique. The health workers' knowledge of these vaccines was assessed using a scale developed for the study. Data collected were analyzed using SPSS version 22. The mean age of the respondents was $31.9 \pm 5.7$ years . Doctors and nurses formed more than half of the respondents, $51.8 \%(\mathrm{n}=114)$. About three quarters of respondents $72.3 \%(n=159)$ had good knowledge of vaccines used in routine immunizations. Knowledge of under-utilized and future vaccine was low with less than a fifth $18.6 \%(n=41)$ and one tenth $9.1 \%(n=20)$ having good knowledge scores respectively. Similarly, poor perception scores of future vaccines were observed in $90.1 \%(n=218)$ of the respondents. Only marital status was associated with knowledge of underutilized vaccines $(\mathrm{p}<0.05)$ and no association was observed between other sociodemographic variables and knowledge of these vaccines $(\mathrm{P}>0.05)$. The awareness level of health care workers on routine immunization is high. Their knowledge and perception of under-utilized and future vaccines were however low. There is, therefore, need for more training and retraining of health care workers on the vaccines.
\end{abstract}

Keywords: Health worker, Knowledge, Under-utilized, Vaccines

\section{INTRODUCTION}

$\mathrm{O}$ ne of the most important ways to improve immunization services is to have parents and health care workers that work towards the benefits of immunization to the growing child. The purpose of the immunization program is to achieve high coverage among children so as to reduce morbidity and mortality that results from vaccine preventable diseases. 'Although the benefit of preventing suffering and death from serious infectious diseases greatly outweighs the rare adverse effect following immunization, ${ }^{2}$ disputes have arisen over the morality, ethics, cost, effectiveness and safety of 
vaccination. ${ }^{2}$ Some vaccination critics say that vaccines are ineffective against disease, or that vaccines safety studies are inadequate. ${ }^{3}$ Some religious groups do not allow vaccination and some political groups oppose mandatory vaccination on the grounds of individual liberty. ${ }^{4,5}$ In the first decade of $21 \mathrm{st}$ century, religious and political leaders with some health care workers $(\mathrm{HCW})$ in northern Nigeria, suspicious of western medicine advised their followers not to have their children vaccinated with oral polio vaccine (OPV). The immunization was suspended for several months. Subsequently, Nigeria reported over 200,000 measles, polio and other vaccine preventable disease (VPD) cases and about 600 deaths from measles in the first quarter of $2008 .^{6}$

Studies have shown that parents and healthcare workers play an essential role in playing improving the number of children reached and ensuring they are fully covered with antigens appropriate for their age. ${ }^{7,8}$ Lack of adequate knowledge on immunization could be a major cause of decline of the vaccine coverage rate, thus training of providers has been found to improve immunization uptake elsewhere. ${ }^{8}$ In a review of evidence on how health care workers determine uptake of immunization it was found that suboptimal vaccination rates resulted from inadequate knowledge among healthcare providers of vaccination schedules, as well as the benefits and side effects. ${ }^{9}$ In some cases, healthcare providers were even found to have misleading beliefs about immunisation and sent unclear or untrue messages to parents. ${ }^{9}$ Nigeria has taken important steps in recent years to address the child mortality burden by increasing vaccine coverage yet, the vaccine coverage fall short of $90 \%$ target, $^{10}$ Scaling up of new and under-used vaccines to $90 \%$ coverage could save more than 600,000 Nigerian children from VPD in the next ten years, and eventually add an economic value equivalent to $\$ 17$ billion to the nation's economy. ${ }^{11,12}$ The study was done at a tertiary health facility in Kano. The state has an estimated maternal mortality ratio of 1600 per 100,000 live births, an under-five mortality of 157 deaths per 1000 births in 2008 . About $13 \%$ of deliveries in the state were attended to by a skilled birth attendant and only $11 \%$ of these deliveries take place in a health care facility. Furthermore, only $6 \%$ of the population receives required vaccination and more than half of the children have not received their immunization. We therefore, assessed the knowledge of routine and underutilized vaccine among $\mathrm{HCW}$ and their perception on future vaccines and how it relates to immunization services in the country.

\section{MATERIALS AND METHODS}

The study was a hospital based cross sectional descriptive study. Kano state has a total of 44 local government areas, and eight of them are metropolitan. The 2018 projected population of the state is 11,401,847 (based on the 2006 National Population Census), with an almost equal distribution of male (51\%) and female (49\%). The health system is organized at three levels namely: primary, secondary and tertiary levels. There are three tertiary health institutions sited in the metropolis; Murtala Mohammed Specialist Hospital, Mohammed Abdullahi Wase Specialist Hospital and Aminu Kano Teaching Hospital. There are an estimated 161 private health facilities distributed across the state. Aminu Kano Teaching Hospital (AKTH) was established on 24th of August 1988. The facility is located along Zaria road in Tarauni Local government area in Kano metropolis. It is a five hundred beds hospital that provides specialized services to patients from Kano and neighbouring states, as well as West Africa countries. The hospital has about 17 departments, 15 wards, laboratory complexes and specialty clinics. The hospital has a staff strength of 2,600 comprising of both administrative and clinical staff. Apart from medical services, the hospital also provides training for medical students, interns, resident doctors and mid-level healthcare workers.

Our study population were health care staff working at health facilities offering immunization in services. The Leslie Fishers formula was used to calculate the minimum size for this study. A total of 220 respondents were selected by cluster sampling technique after meeting up the inclusion criteria. A semi-structured interviewer administered questionnaire was developed and pre-tested for the study. The questionnaire captures information on the socio-demography of the respondents, knowledge of health care workers on routine immunization, new and under-utilized vaccines as well as the perception of the health workers toward future vaccine. The knowledge of routine, underutilized and future vaccine was assessed based on a scoring system developed for the study. Each positive response has one mark score and a zero score for a wrong response. The maximum score obtainable was 21 for assessment of knowledge of routine vaccines (score of 0 10 considered as poor knowledge, and scores of 11-21 was considered good knowledge). Similarly, the maximum score obtainable for assessment of knowledge of underutilized vaccines was 52-point scale (score of 0-26 graded as poor 
knowledge, and scores of 27-52 was considered good knowledge). Assessing the knowledge of future vaccines was a 7-point scale with scores of 0-3 considered as poor knowledge and scores of 4-7 good knowledge score. Perception towards future vaccine was analyzed using Likert's scale and also graded as good on a scale of 11- 20 score and poor perception if it is between 0-10 score. The maximum score on the perception scale was 20 points. Data were entered manually into a spreadsheet on Microsoft excel and analyzed using SPSS Version 22. Quantitative data were summarized using mean, standard deviation, while Qualitative data were presented using frequency tables. Tests of associations between categorical data was performed, Chisquare test of association was used to test for statistically significant associations. A P-value of 0.05 or less was considered significant.

Ethical approval for this study was obtained from ethical committee of Aminu Kano Teaching Hospital and Kano State Hospital Management Board ethical committee. All respondents were made to sign consent before participating and assurances were given on confidentiality of data collected.

\section{RESULTS}

Of the 220 respondents that participated, $124(56.36 \%)$ were males, and 96(43.64\%) were females. The mean age of the respondents was 31.9 with a standard deviation of 5.7 years. All the respondents were drawn from a tertiary health facility.

Table 1: Sociodemographic characteristics of the respondents

\begin{tabular}{lll}
\hline $\begin{array}{l}\text { Socio demographic } \\
\text { features }\end{array}$ & $\begin{array}{l}\text { Frequency } \\
\text { N=220 }\end{array}$ & Percentage \\
\hline Age groups (years) & 10 & \\
$15-24$ & 146 & 4.6 \\
$25-34$ & 56 & 66.4 \\
$35-44$ & 8 & 25.5 \\
$45-54$ & 124 & 3.6 \\
Sex & 96 & 56.4 \\
Male & & 43.6 \\
Female & 128 & \\
Ethnic group & 32 & 58.2 \\
Hausa & 29 & 14.6 \\
Igbo & 31 & 13.3 \\
Yoruba & & 14.1 \\
others & 76 & 34.5 \\
Marital Status & 143 & 65.0 \\
single & 1 & 0.5 \\
married & & \\
widowed & 60 & 27.3 \\
Professional Qualification & 54 & 24.5 \\
Doctor & 53 & 24.1 \\
Nurse & 26 & 5.5 \\
CHEW & 12 & 6.8 \\
Lab Scientist & 15 & 47.3 \\
Technician & & 31.8 \\
Others & 104 & 17.7 \\
Years of Service & 70 & \\
Less than 5 & 39 & \\
5-10 & 7 & \\
11 -15 & & \\
16-20 & &
\end{tabular}

Table 2: Knowledge of routine immunization vaccines

\begin{tabular}{lll}
\hline Knowledge Assessed (n=220) & $\begin{array}{l}\text { Correct knowledge } \\
\text { F (\%) }\end{array}$ & $\begin{array}{l}\text { Incorrect knowledge } \\
\text { F (\%) }\end{array}$ \\
\hline Ever heard of routine Immunization vaccines & $220(100.0)$ & $0(0.0)$ \\
Facility offers vaccine for Immunization & $220(100.0)$ & $0(0.0)$ \\
Knows RI vaccine Schedule & $173(78.6)$ & $47(21.4)$ \\
Knows appropriate vaccine for age & $175(79.5)$ & $45(20.5)$ \\
Knows Vaccine preventable diseases & $218(99.1)$ & $2(0.9)$ \\
Knows when to start child Immunization & $220(100.0)$ & $0(0.0)$ \\
Knows Adverse events following Immunization & $131(59.5)$ & $89(40.5)$ \\
Knows Contraindications to Immunization & $115(52.3)$ & $105(47.7)$ \\
\hline
\end{tabular}

Table 3: Knowledge of Underutilized Vaccine among HCW

\begin{tabular}{|c|c|c|}
\hline Knowledge Assessed $(\mathrm{n}=\mathbf{2 2 0})$ & $\begin{array}{l}\text { Correct Knowledge } \\
\text { Freq }(\%)\end{array}$ & $\begin{array}{l}\text { In Correct Knowledge } \\
\text { Freq }(\%)\end{array}$ \\
\hline Aware of Underutilized vaccines & $119(54.1)$ & 101(45.9) \\
\hline \multicolumn{3}{|l|}{ Vaccines Identified as Under Utilized } \\
\hline Pneumococcal conjugate vaccine & $62(28.2)$ & $158(71.8)$ \\
\hline Typhoid Vaccine & $57(25.9)$ & $163(74.1)$ \\
\hline Influenza vaccine & $48(21.8)$ & $172(78.2)$ \\
\hline Hepatitis A vaccine & $42(19.1)$ & $178(80.9)$ \\
\hline Hepatitis B vaccine & $77(35.0)$ & $143(65.0)$ \\
\hline Yellow fever vaccine & $30(13.6)$ & $190(86.4)$ \\
\hline Rubella & $23(10.5)$ & $197(89.6)$ \\
\hline Rotavirus vaccine & $23(10.5)$ & $197(89.6)$ \\
\hline Cholera Vaccine & $40(18.1)$ & $180(81.8)$ \\
\hline Meningococcal conjugate vaccine & $69(31.4)$ & $151(68.6)$ \\
\hline Hemophilus Influenza type $b$ vaccine & $58(26.4)$ & $162(73.6)$ \\
\hline Human papilloma Virus Vaccine & $75(34.1)$ & $145(65.9)$ \\
\hline \multicolumn{3}{|l|}{ Pneumococcal Vaccine } \\
\hline Knows target population & $75(65.9)$ & $145(34.1)$ \\
\hline Knows disease conditions it protects & $59(26.8)$ & $161(73.2)$ \\
\hline Knows number of doses required for protection & $2(0.9)$ & $218(99.1)$ \\
\hline Knows availability & $47(21.4)$ & $173(78.6)$ \\
\hline \multicolumn{3}{|l|}{ Typhoid Vaccine } \\
\hline Knows target population & $6(2.7)$ & $214(97.3)$ \\
\hline Knows disease conditions it protects & $54(24.4)$ & $166(75.5)$ \\
\hline Knows number of doses required for protection & $3(1.4)$ & $217(98.6)$ \\
\hline Knows availability & $28(12.7)$ & $192(87.3)$ \\
\hline \multicolumn{3}{|l|}{ Influenza Vaccine } \\
\hline Knows target population & $44(20.0)$ & $176(80.0)$ \\
\hline Knows disease conditions it protects & $50(22.7)$ & $170(77.3)$ \\
\hline Knows number of doses required for protection & $5(2.3)$ & $215(97.7)$ \\
\hline Knows availability & $45(20.5)$ & $175(79.5)$ \\
\hline \multicolumn{3}{|l|}{ Hepatitis A Vaccine } \\
\hline Knows target population & $80(36.4)$ & $140(63.6)$ \\
\hline Knows disease conditions it protects & $76(34.5)$ & $144(65.5)$ \\
\hline Knows number of doses required for protection & $10(4.5)$ & $210(95.5)$ \\
\hline Knows availability & $40(18.2)$ & $180(81.8)$ \\
\hline \multicolumn{3}{|l|}{ Hepatitis B Vaccine } \\
\hline Knows target population & $110(50.0)$ & $110(50.0)$ \\
\hline Knows disease conditions it protects & $105(47.7)$ & $115(52.3)$ \\
\hline Knows number of doses required for protection & $60(27.3)$ & $160(72.7)$ \\
\hline Knows availability & $95(43.2)$ & $125(56.8)$ \\
\hline \multicolumn{3}{|l|}{ Rota virus Vaccine } \\
\hline Knows target population & $26(11.8)$ & $194(88.2)$ \\
\hline Knows disease conditions it protects & $39(17.7)$ & $181(82.3)$ \\
\hline Knows number of doses required for protection & $7(3.2)$ & $213(96.8)$ \\
\hline Knows availability & $7(3.2)$ & $173(96.8)$ \\
\hline \multicolumn{3}{|l|}{ Cholera Vaccine } \\
\hline Knows target population & $77(35.0)$ & $143(65.1)$ \\
\hline Knows disease conditions it protects & $76(34.5)$ & $144(65.5)$ \\
\hline Knows number of doses required for protection & $13(5.9)$ & $218(94.1)$ \\
\hline Knows availability & $30(13.6)$ & $190(86.4)$ \\
\hline \multicolumn{3}{|l|}{ Meningococcal Vaccine } \\
\hline Knows target population & $32(14.5)$ & $188(85.5)$ \\
\hline Knows disease conditions it protects & $84(38.2)$ & $136(61.8)$ \\
\hline Knows number of doses required for protection & $7(3.2)$ & $203(96.8)$ \\
\hline Knows availability & $63(28.6)$ & $157(71.4)$ \\
\hline \multicolumn{3}{|l|}{ Hib Vaccine } \\
\hline Knows target population & $67(30.5)$ & $153(69.5)$ \\
\hline Knows disease conditions it protects & $56(25.5)$ & $164(74.6)$ \\
\hline Knows number of doses required for protection & $13(5.9)$ & $207(94.1)$ \\
\hline Knows availability & $43(19.6)$ & $177(80.4)$ \\
\hline \multicolumn{3}{|l|}{ HPV Vaccine } \\
\hline Knows target population & $76(34.6)$ & $144(65.4)$ \\
\hline Knows disease conditions it protects & 85 (38.6) & $135(61.4)$ \\
\hline Knows number of doses required for protection & $11(5.0)$ & $209(95.0)$ \\
\hline Knows availability & $43(19.6)$ & $177(80.5)$ \\
\hline
\end{tabular}


All the healthcare workers studied are aware of vaccines used in routine immunization and know when a child should start receiving vaccines. More than half of the respondents 131 (59.5) were able to mention at least three adverse events that could follow immunization in a child.

The respondents were assessed on underutilized vaccine. The responses are shown in table 2 above.

Table 4: Perception of Future Vaccines Amongst Health care workers

\begin{tabular}{|c|c|c|c|}
\hline Perception & $\begin{array}{l}\text { Incorrect } \\
F(\%)\end{array}$ & $\begin{array}{l}\text { Correct } \\
\text { F }(\%) \\
\end{array}$ & $\begin{array}{l}\text { Undecided } \\
\mathrm{F}(\%)\end{array}$ \\
\hline \multicolumn{4}{|l|}{ When planning to introduce new vaccine we consider: } \\
\hline Vaccine efficacy & $220(100.0)$ & & \\
\hline Vaccine effectiveness & $218(99.9)$ & $0(0)$ & $2(0.1)$ \\
\hline Severity of disease & $209(95.0)$ & $7(3.2)$ & $4(1.8)$ \\
\hline Burden of disease & $206(93.6)$ & $12(5.5)$ & $2(0.9)$ \\
\hline Risk to contacts & $202(91.8)$ & $16(6.8)$ & $3(1.4)$ \\
\hline Public concerns & $193(87.7)$ & $25(11.4)$ & $2(0.1)$ \\
\hline Coverage & $211(95.9)$ & $6(2.7)$ & $3(1.4)$ \\
\hline \multicolumn{4}{|l|}{ When introducing a vaccine in to community consider: } \\
\hline Supply issues & $216(98.2)$ & $4(1.8)$ & - \\
\hline logistics associated with the new vaccine. & $208(94.6)$ & $10(4.5)$ & $2(0.9)$ \\
\hline economic and financial issues & $211(95.9)$ & $8(3.6)$ & $1(0.4)$ \\
\hline \multicolumn{4}{|l|}{ Introducing a new vaccine means you have to: } \\
\hline Revise the practice guidelines & $163(74.1)$ & $48(21.8)$ & $9(4.1)$ \\
\hline Revise of Road-to-Health charts & $151(68.6)$ & $59(26.8)$ & $10(4.6)$ \\
\hline Training of health workers & $169(76.8)$ & $51(23.2)$ & \\
\hline Cold chain Logistics and Manuals, & $189(85.9)$ & $25(11.4)$ & $6(2.7)$ \\
\hline Information, Education and Communication for the public & $207(94.1)$ & $12(5.5)$ & $1(0.4)$ \\
\hline Monitoring of Adverse Events & $210(95.5)$ & $8(3.6)$ & $2(0.9)$ \\
\hline Surveillance of the disease in question. & $204(92.7)$ & $12(5.5)$ & $4(1.8)$ \\
\hline You can monitor the success of a new vaccine by: & & & \\
\hline Estimating the burden of the disease, & $205(93.2)$ & $12(5.5)$ & $3(1.4)$ \\
\hline Determining the Effectiveness of the vaccine, & $211(95.9)$ & $8(3.6)$ & $1(0.4)$ \\
\hline Determining the Coverage achieved & $213(96.8)$ & $7(3.2)$ & \\
\hline
\end{tabular}

Table 5: Knowledge and Perception of the respondent on Vaccines

\begin{tabular}{lll}
\hline Assessment & \multicolumn{2}{l}{ Frequency Percentage } \\
\hline Knowledge of Routine Vaccine & & \\
Good (score 11-21) & 159 & 72.3 \\
$\begin{array}{l}\text { Poor (score 0-10) } \\
\text { Knowledge of Underutilized vaccine }\end{array}$ & 61 & \\
Good (score 27-52) & & \\
Poor (score 0-26) & 41 & 18.6 \\
& 179 & 81.4 \\
Knowledge of Future Vaccines & & \\
Good (score 4-7) & 20 & 9.1 \\
Poor (score 0-3) & 200 & 90.9 \\
\hline Perception of FutureVaccines & & \\
Good Perception (score 11-20) & 2 & 0.9 \\
Poor Perception (score 0-10) & 218 & 90.1 \\
\hline
\end{tabular}

Fewer respondents have been observed to have good perception $0.9 \%(n=20)$, knowledge of future $9.1 \%(\mathrm{n}=20)$ and underutilized vaccines $18.6 \%(\mathrm{n}=41)$ from the study.
Table 6: Relationship between Sociodemographic features and Knowledge of Vaccines

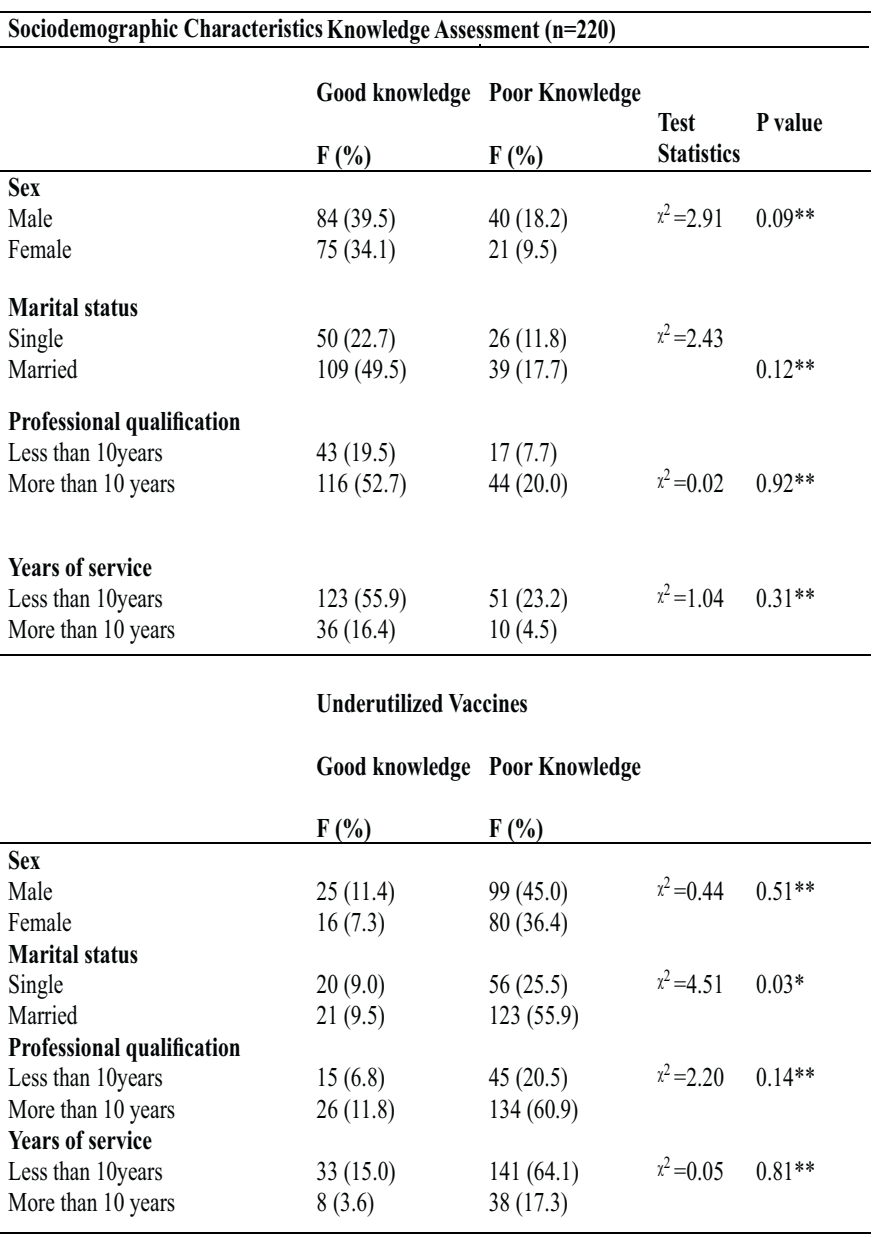

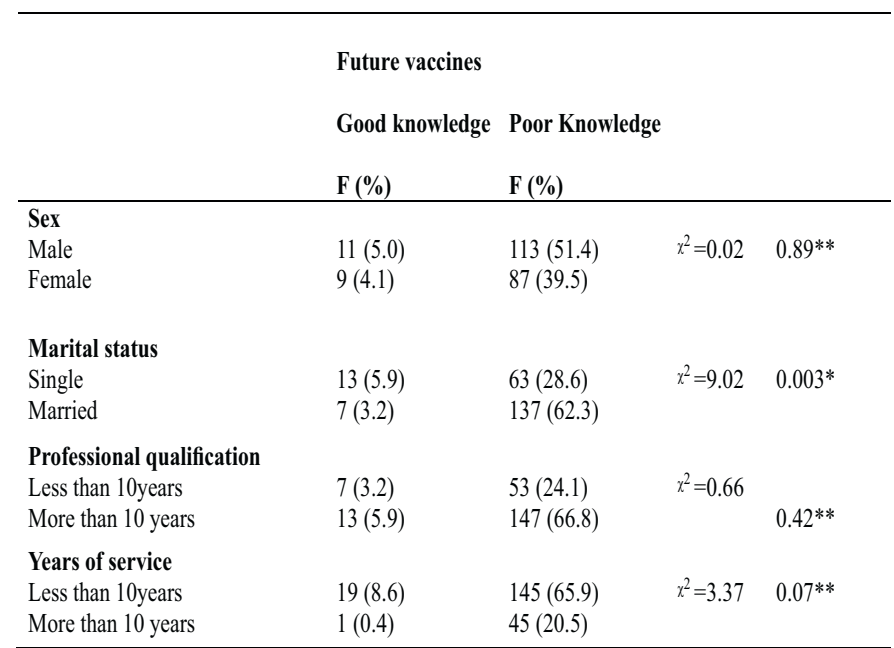

\section{DISCUSSION}

Good knowledge of vaccines used in routine immunizations was observed among the respondents, however knowledge of underutilized as well as future vaccine was poor. Awareness of routine immunization was high similar to what was 
reported by other studies, ${ }^{12,13}$ however differs from findings here because caregivers were used as study population in these studies. Inadequate parental knowledge and information and that of healthcare workers could grossly affect the uptake and utilization of childhood immunization as reported by many studies. ${ }^{14,15}$, If the main problem among healthcare providers is lack of knowledge, in most cases, suboptimal vaccination rates result from this inadequate knowledge and will affect vaccination schedules and benefits.Vaccines against hepatitis B, Hemophilus influenza type b, yellow fever, rubella, typhoid and cholera have been widely available in industrialized countries for years, but are underutilized effectively in developing countries. New formulations or combination vaccines that decrease the number of injections, overcome vaccine wastage, and improve actual and perceived adverse event profile of the vaccines are available. Our study demonstrated poor knowledge of future and underutilized vaccines. Where the healthcare worker does not have adequate information on the vaccines used, it will undoubtedly affect uptake, coverage and utilization. Healthcare providers ranked first among most used and most trusted sources of information on vaccines as reported from studies in western Europe. ${ }^{17-19}$

Healthcare workers routinely provide information about recommended vaccinations to their patients and informed them about benefits and risks. When the healthcare providers sounded vague, some parents may interpret this as concern that the vaccine was unsafe. ${ }^{20}$ Furthermore, if healthcare workers' knowledge was found to be inadequate, vaccination coverage in the general population may decrease. The same happens when healthcare workers were reported to have a relaxed attitude towards immunization, which is itself a consequence of lack of knowledge and may lead to more problems. ${ }^{9}$ We observed a very low perception to future vaccines. This differs to what was reported from Netherland, ${ }^{21}$ where $43 \%$ of the respondents were reported to have positive perception and attitudes towards all vaccinations including the new vaccines. Perhaps because the caregivers were used as the respondents in Netherland study. An extensive range of vaccines are in the development pipeline against many diseases of public health importance. Only marital status was found to be positively associated with Knowledge of vaccines $(p<0.05)$. Contrary to what was reported by other studies where years of service and professional qualification plays a major role in the knowledge of health worker.

\section{CONCLUSION}

Healthcare workers were found to have a high knowledge of routine immunization vaccine but poor knowledge of future and underutilized vaccine. The perception of future vaccine was also observed to be low. The need to have training and more information on future and underutilized vaccine will go a long way in improving the utilization of some of these new and utilized vaccines in our community.

\section{Recommendation}

It is recommended from this study that healthcare workers that work in immunization units of our health facilities should have regular training and skills updates to enable them tackle the challenges of immunization in Nigeria. This will improve uptake, utilization and coverage of immunization services among the population.

\section{Limitation}

Our study has been limited by the fact that the health workers were drawn from the same facility but their selection followed a clearly laid down scientific procedure to eliminate any form of bias.

\section{Acknowledgement}

We acknowledge the cooperation given to us by the Kano state Ministry of Health Research board, the head of the tertiary facility used as well as the healthcare workers that participated in this study.

\section{Conflict of Interest}

None declared.

\section{REFERENCES}

1. Bolanle B. V, Abimbola O.O, Olusola M.:Impact of training intervention on immunization providers' knowledge and practice of routine immunization in Ibadan, south-western Nigeria: a primary health care experience Pan African Medical Journal. 2017;26: 216. doi:10.11604/pamj.2017.26.216.11545

2. Sinal SH, Cabinum-Foeller E, Socolar R. Religion And Medical Neglect. Southern Medical Journal2008;101(7):703-706

3. Halvorsen R, The truth about vaccines. The Brit J of Gen Pract2007;57:(542):679-757

4. Demichili V, Jefferson T, RivettiA, Price D. Vaccines For Measles Mumps and Rubella In Children. Pub med journal ;2005:19(4)

5. Basin H. The Ethics Of vaccine Usage In the Society; 
Lessons from the past. Pub med Journal; 2001:25(30):104-108

6. Clement CJ, Green nough P, Shull D. How Vaccine Policy Can become political- The example of polio in Nigeria: Current Drug Safety journal 2006: 1(1):117119

7. Al-lela OQ, Bahari MB, Salih MR, Al-Abbassi MG, Elkalmi RM, Jamshed SQ. Factors underlying inadequate parents' awareness regarding pediatrics immunization: findings of cross-sectional study in Mosul- Iraq. BMC Pediatr. 2014; 14: 29.

8. Anastasi D, Di Giuseppe G, Marinelli P, Angelillo IF. Paediatricians knowledge, attitudes, and practices regarding immunizations for infants in Italy. BMC Public Health. 2009; 9: 463.

9. Simone B, Carrillo-Santisteve P, Lopalco PL. Healthcare workers' role in keeping MMR vaccination uptake high in Europe: a review of evidence. Euro Surveill. 2012;17(26):pii=20206. Available online: http://www.eurosurveillance.org/ViewArticle.aspx? Articleld $=20206$

10. Endurance A. Ophori, Musa Y. Tula ,Azuka V. Azih, Rachel Okojie and Precious E. Ikpo. Review of Current Trends of Immunization in Nigeria: Prospect and Challenges. Tropical Medicine and Health. 2014;. 42 .(2), , 67-75 doi: 10.2149/tmh.2013-13

11. NPHCDA: Routine Immunization Strategic plan in Nigeria 2013-2015. Available on http://www.nationalplanningcycles.org/sites/default Lfiles/country docs/Nigeria/ri strategic plan combi ned mahmud draft 1.pdf. Date accessed??

12. Deady J. Thornlon L. Parent's knowledge of and attitude towards the primary childhood immunizations. Ireland Med Journal. 2005 ; 98 (1): 7 - 8

13. Kabir M, Ilyasu Z, Abubakar I.S Gajida A.U. knowledge perception and beliefs of mothers on routine childhood immunization in a northern Nigerian village. Annals of Nigerian medicine2005; 1 , . (1) 21-26

14. Kabir M, Abubakar I.S Iliyasu Z. and Nwosuh J.I Immunization coverage in children below 2 years of age in Fanshekara Kano State Nigeria. Journal of basic and clinical sciences, 2004;1 .(1):, $10-13$.

15. Hamlin $\mathrm{J}$, et al: Inappropriately timed immunizations: types, causes, and their relationship to record keeping. Am J Public Health 1996,86(12):1812-1814.

16. Hariweni $\mathrm{T}$, et al: Knowledge, attitude, and practice of underfive children stimulation of working and nonworking mothers. PaediatrIndones 2004,44(3-4):101-105

17. Attitudes Knowledge and practice of health professionals regarding immunization. Australian and New Zealand journal of public health.2008: ???...224225

18. Pantha S, Pragya GS. Knowledge awareness and practices of Hepatitis A and $B$ vaccination among medical students of Chittagong medical college. European journal of hepato-gastro enterology; 2011:1(1):23-25
19. Cotter S, Ryan F, Hegarty H, McCabe TJ, Keane E. Immunisation: the views of parents and health professionals in Ireland. Euro Surveillance. 2003; 8(6). Available from: http://www.eurosurveillance.org/ViewArticle.aspx?Arti cleId=416 .[Accessed 5th July 2012].

20. Hilton S, Petticrew M, Hunt K. Parents' champions vs. vested interests: who do parents believe about MMR? A qualitative study. BMC Public Health. 2007;7:42.

21. Hak, E, Schonbeck,Y, De Melker H, Van EssenGA. Negative attitude of highly educated parents and health care workers towards future vaccination in the Dutch childhood vaccination program. Elsevier Journal; 2005:23(24)3103-3107 